Pharmacology

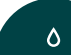

CiteScore: $\mathbf{5 . 8}$

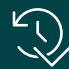

Time to final decision 9 weeks

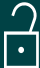

DOAJ

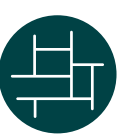

New Section:

Registered Reports

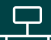

古品

PMC

editorialoffice mca@ karger.com karger.com/mca

$N$ Twitter

\title{
Medical Cannabis and Cannabinoids
}

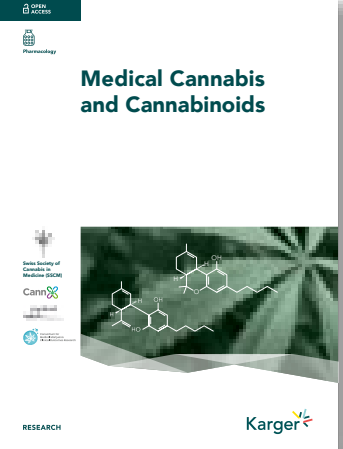

International forum examining cannabis for medical purposes

Medical Cannabis and Cannabinoids is a peer-reviewed journal offering an international forum to present and discuss recent advances in the rapidly developing and challenging field of the medical use of cannabis and cannabinoids. It seeks to bridge the gap between empirical and evidence-based clinical medicine by covering current basic and applied as well as translational research topics. In addition to original papers, reviews, and mini-reviews, this journal features short communications, case reports, technical notes, letters, and conference proceedings.
Official Journal of

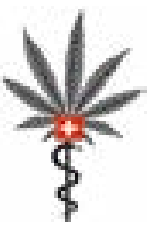

Affiliated with

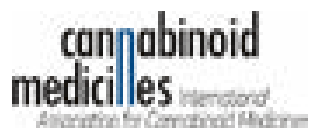

